\title{
Research on cogging torque optimization design of permanent magnet synchronous wind turbine
}

\author{
Lei Chen ${ }^{1}$,Zuoxia Xing ${ }^{1}$, Bowen $\mathrm{Zhu}^{1,{ }^{*}, \text { Dongrui Wang }}{ }^{1}$, Yuzhang Gao ${ }^{1}$, and Xiaoqi Wang ${ }^{2}$ \\ ${ }^{1}$ Shenyang University of Technology, School of Electrical Engineering, Liaoning Province 110870, \\ China \\ ${ }^{2}$ Yanfeng Bioo (Shenyang) Automotive Exterior Systems Co., Ltd., Liaoning Province 110027, China
}

\begin{abstract}
Cogging torque is one of the unique problems of permanent magnet generators. Its main cause is the uneven distribution of the generator's magnetic permeability, which directly affects the starting and running performance of the generator. The study of cogging torque suppression methods is of great significance for improving the operating stability and service life of generators. Through the analysis of the principle of cogging torque, an optimization method for the amplitude of cogging torque based on Taguchi algorithm for the two parameters of pole arc coefficient and skew angle is established. And the finite element analysis method is used to quantitatively compare the characteristic parameters of the generator model before and after the optimization by Taguchi algorithm. The results show that when the pole arc coefficient and the angle of the chute are in the optimal value at the same time, the cogging torque of the generator can be greatly reduced, and its air gap magnetic density waveform and induced electromotive force waveform are ideal, which provides a research method for the design and parameter optimization of large megawatt permanent magnet synchronous wind turbines.
\end{abstract}

\section{Introduction}

Permanent magnet synchronous motors are widely used in the research and development of wind power generators. Compared with excitation generators, they have the advantages of high torque-to-current ratio, high torque-to-volume ratio, high efficiency, small size and simpler structure. Due to the existence of the stator core slot of the permanent magnet synchronous generator, the interaction between the stator teeth and the magnetic steel during the operation of the generator will cause the change of the magnetic field, which will lead to the torque pulsation caused by the cogging torque [1], It will cause unnecessary vibration and noise of the generator, and even reduce its dynamic performance to a certain extent. Therefore, the influence of cogging torque on the performance of the generator must be considered in the design process of permanent magnet wind turbines [2].

\footnotetext{
*Corresponding author: 630653599@qq.com
} 
There are many factors that affect the magnitude of the cogging torque, such as the stator and rotor materials, different permanent magnet materials and structures. In engineering, the cogging torque is mainly suppressed by changing the structure design of the generator body. Literature [3] [6] studied the influence of the optimal combination of stator cogging parameters, armature slot width and pole arc coefficient on cogging torque; Literature [7] studied the influence of surface auxiliary grooves on cogging torque, and calculated the number of auxiliary grooves by multi-objective genetic algorithm; Literature [8] studied the influence of cogging torque on noise; Literature [9] [15] carried out research and simulation work on cogging torque suppression methods; In the optimization algorithm of cogging torque, literature [16] uses genetic algorithm to optimize the cogging torque of the external rotor motor; Literature [17] optimized the cogging torque of lowspeed permanent magnet motors based on the RBF approximation model; Literature [18] [20] used Taguchi algorithm to optimize the structural parameters of permanent magnet synchronous motors.

In this paper, two models of $10 \mathrm{MW}$ permanent magnet synchronous wind turbine are designed based on the research of cogging torque. Based on Taguchi algorithm, the cogging torque of the two motors is optimized by two optimization factors: the pole arc coefficient and the inclined slot angle. After determining the best combination plan, compare the cogging torque under a variety of pole arc coefficients and skew angle assembly plans, and analyze the influence of the cogging torque on the performance of the generator. The effectiveness of the method is verified by the simulation test of two generator design schemes.

\section{Analysis of cogging torque generation mechanism of permanent magnet generator}

\subsection{Generation mechanism of cogging torque}

In the process of generator design, the problem of cogging torque is always an unsolved problem. The energy method is usually used to calculate cogging torque. Because the difference of permeance between the stator teeth and the segmented permanent magnet is small, the magnetic field around the stator teeth basically remains unchanged. However, the permeance of the stator teeth between the permanent magnets in the two adjacent magnetic sleeves will change, which will cause the change of energy stored in the magnetic field of the motor, The method of calculating the cogging torque usually uses the energy method. The magnetic permeability between the stator teeth and the segmented permanent magnets changes very little, so the magnetic field around the stator teeth remains basically unchanged. However, the magnetic permeance of the stator tooth area between the permanent magnets in two adjacent magnetic sleeves changes, which will cause the change of the stored energy of the motor magnetic field and generate cogging torque $\mathrm{T}_{\operatorname{cog}}(\alpha)$. The calculation formula is:

$$
\mathrm{T}_{\operatorname{cog}}(\alpha)=-\frac{\partial W}{\partial \alpha}
$$

Where $\alpha$ is the angle between the centerline of the stator teeth and the centerline of the permanent magnet. Without considering the saturation of the magnetic field, the energy stored in the magnetic field of the motor can be approximately regarded as the energy in the 
air gap between the armature tooth and the permanent magnet. The stored energy of the magnetic field of the motor can be expressed as:

$$
W \approx W_{\text {airgap }+\mathrm{PM}}=\frac{1}{2 \mu_{0}} \int_{V} B^{2} d V
$$

Where $W_{\text {argap } \mathrm{PM}}$ is the energy in the air gap between the armature tooth and the permanent magnet. $\mu_{0}$ is the permeability of air. $B$ is the magnetic induction intensity. $V$ is the air gap volume between the armature tooth and the permanent magnet.

The air gap flux density between the stator teeth and the permanent magnets along the surface of the permanent magnet synchronous motor stator armature can be approximately expressed as:

$$
B(\theta, \alpha)=B_{r}(\theta) \frac{h_{m}(\theta)}{h_{m}(\theta)+\delta(\theta, \alpha)}
$$

Where $\theta$ is the angle between the permanent magnet and the rotor shaft when it moves in the circumferential direction. $h_{m}(\theta)$ is the thickness of the permanent magnet pole. $B_{r}(\theta)$ is the remanence of permanent magnets. $\delta(\theta, \alpha)$ is the distribution coefficient of the effective air gap length of the permanent magnet along the circumferential direction;

Substituting formula (3) into formula (2), the stored energy of the motor's magnetic field is obtained:

$$
W=\frac{1}{2 \mu_{0}} \int_{V} B_{r}^{2}(\theta)\left(\frac{h_{m}(\theta)}{h_{m}(\theta)+\delta(\theta, \alpha)}\right)^{2} d V
$$

Assuming that the magnetic flux of each stage of the generator is constant, expand A through Fourier transform to get the following formula:

$$
B_{r}^{2}(\theta)=B_{s 0}+B_{s N} \cos (2 n p \theta)
$$

Where: $B_{s n}$ is the $N$-th Fourier expansion coefficient of $7 ; p$ is the number of generator pole pairs. that is:

$$
\xi(\theta, \alpha)=\left[\frac{h}{h+g(\theta, \alpha)}\right]
$$

Fourier decomposition of A:

$$
\xi^{2}(\theta, \alpha)=\xi_{s 0}+\sum_{n=1}^{\infty} \xi_{s N} \cos [N z(\theta+\alpha)]
$$

Where: $\xi_{s N}$ is the N-th Fourier expansion coefficient of $\xi^{2}(\theta, \alpha)$. From this, the general expression of cogging torque can be obtained as:

$$
T_{c}=\frac{L_{e f} N_{s} \pi}{4 \mu_{0}}\left(R_{2}^{2}-R_{1}^{2}\right) \sum_{n=1}^{\infty} n \xi_{s N} B_{r\left(\frac{N z}{2 p}\right)} \sin \left(n N_{s} \alpha\right)
$$


Where: $L_{e f}$ is the axial length of the generator; $N_{s}$ is the number of generator slots; $\mathrm{R}_{1}$ is the inner radius of the air gap; $\mathrm{R}_{2}$ is the outer radius of the air gap;

It can be seen that both $B_{r}^{2}(\theta)$ and $\xi^{2}(\theta, \alpha)$ are the influencing factors of the amplitude of the cogging torque and the waveform. But not all the Fourier expansion series have an effect on the cogging torque waveform. For $B_{r}^{2}(\theta)$, only the $\mathrm{Nz} / 2 \mathrm{p}$ expansion series have an effect. For $\xi^{2}(\theta, \alpha)$, only the $n$-th Fourier expansion series has an effect on the cogging torque, so if $B_{\mathrm{r} \frac{N \frac{2}{2 p}}{2 \mathrm{p}}}(\theta)$ and $\xi^{2}(\theta, \alpha)$ can be reduced as much as possible, the cogging torque can be effectively suppressed.

For a permanent magnet generator with the same magnetic pole shape and size and the same effect, the expression of the number of cycles $N_{p}$ of the cogging torque within a tooth pitch is:

$$
N_{\mathrm{p}}=\frac{2 \mathrm{p}}{\operatorname{GCD}(2 \mathrm{p}, \mathrm{Q})}
$$

Among them, $\operatorname{GCD}(2 \mathrm{p}, \mathrm{Q})$ is the greatest common divisor of the number of slot poles.

\subsection{Introduction to Taguchi's algorithm mechanism and optimization process}

Taguchi algorithm is an experimental method developed by Dr. Genichi Taguchi of Japan. It is a low-cost and high-efficiency quality engineering calculation method based on the idea of local optimization. The optimization flow chart is as follows:

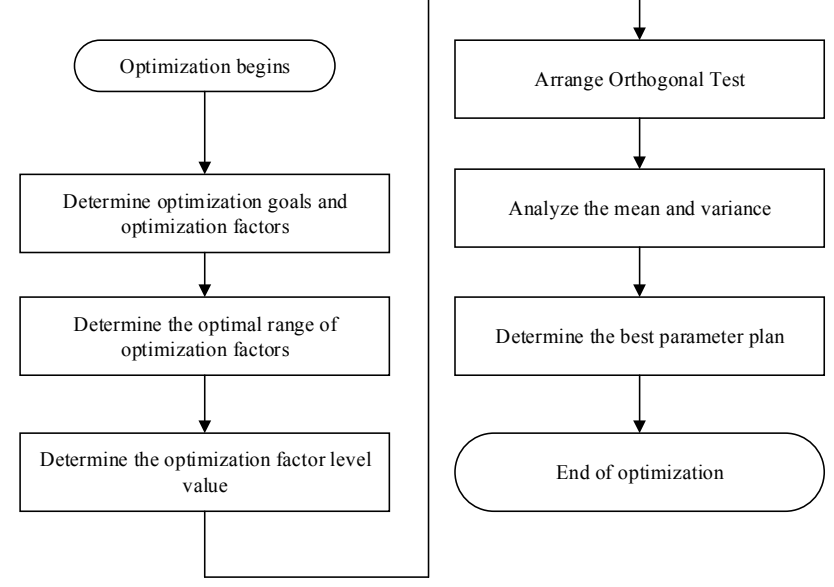

Fig. 1. Optimization flow of Taguchi Algorithm.

\subsection{Selection of optimization goals and optimization factors}

Taguchi method can achieve multi-objective optimization. The optimization target is the dependent variable in the experiment, and the optimization factor is the independent variable in the experiment. In the work of this article for the design of generators, two indexes of motor efficiency and cogging torque are selected as optimization targets. In the process of selecting the optimization factor, the parameters that have a more obvious impact on the optimization goal should be selected. In addition By skewing the stator, the unfavorable factors such as the harmonic amplitude in the air gap magnetic density 
waveform can be reduced to reduce the cogging torque. Therefore, the angle of the stator skewer is also used as an optimization factor.

\subsection{Determine the optimal range and level of optimization factors}

Through the traditional generator design method and the RMxprt module, the above two optimization factors are parameterized, and the performance of the optimization target under different parameter factors is obtained. According to different performances, determine the optimal range of optimization factors, divide the optimization factors into $3 \sim 5$ equidistantly, and name the level values of each optimization factor respectively in order.

\subsection{Determine the optimal range and level of optimization factors}

Orthogonal experiment can optimize the level of multiple factors, has the important characteristics of being scattered, neat and comparable, and can greatly reduce the number of experiments and save the cost of experiments. Orthogonal table can generally be expressed as $L_{n}\left(A^{k}\right)$, where: represents the number of experiments; A represents the number of level values; $k$ represents the number of optimization factors. The finite element simulation experiment was carried out according to the orthogonal table, and the optimized target value of the optimized silver under different combinations was obtained.

\subsection{Analysis of the mean and variance}

In order to analyze the influence of the change of the optimization factor on each performance index of the motor, and the proportion of the influence, the average value of the optimization factor at different levels must be analyzed first. For example, the average value of the cogging torque of the integer slot scheme when the pole arc coefficient is level A1 is:

$$
T_{\operatorname{cog}}\left(\alpha_{p 1}\right)=\frac{1}{4}\left(T_{\operatorname{cog}}(1)+T_{\operatorname{cog}}(2)+T_{\operatorname{cog}}(3)+T_{\operatorname{cog}}(4)+T_{\operatorname{cog}}(5)\right)
$$

Where: $T_{\operatorname{cog}}\left(\alpha_{p 1}\right)$ is the cogging torque at level 1 for the optimization factor polar arc coefficient $. T_{\operatorname{cog}}(1), T_{\operatorname{cog}}(2), T_{\operatorname{cog}}(3), T_{\operatorname{cog}}(4), T_{\operatorname{cog}}(5)$ are respectively the cogging torque in the first $1,2,3,4$, and 5 tests.

In the same way, the average value of generator performance indicators at different levels of other optimization factors can be calculated.

In the analysis of variance, we must first calculate the overall average (SS) of each performance index. Secondly, calculate the variance (SSF), the formula is as follows:

$$
\begin{gathered}
S S=\frac{1}{50} \sum_{1}^{50} T_{c o g}(i) \\
S S F\left(T_{c o g}\right)=\frac{1}{\lambda} \sum_{i=1}^{\lambda}\left(T_{c o g}(i)-S S\left(T_{\operatorname{cog}}\right)\right)^{2}
\end{gathered}
$$


Where: $S S\left(T_{\operatorname{cog}}\right)$ is the average value of the cogging torque; $T_{\operatorname{cog}}(i)$ is the cogging torque in the $\mathrm{i}$-th test; $\operatorname{SSF}\left(T_{\text {cog }}\right)$ is the variance value of the cogging torque of the generator, and $\lambda$ is the level number of each parameter.

In the same way, the motor performance variance and proportion of each optimization factor at 5 levels can be calculated, and the best combination of optimization factors can be determined according to the variance calculation results.

\section{Taguchi algorithm optimization process}

\subsection{Determination of optimization factors and optimization goals}

For two permanent magnet synchronous generators, the respective motor efficiency $\eta$ and cogging torque $T_{\operatorname{cog}}$ are selected as the optimization targets. Select the respective pole arc coefficient $\alpha_{p}$ and skew angle $\operatorname{Skew}_{(\theta)}$ as the optimization factor.

\subsection{Determination of preferred range and level value}

Because the two prototypes have the same capacity and similar structure, they are both built-in synchronous wind turbines. Therefore, for the convenience of calculation, the same optimization range is selected for the two optimization factors. The design parameters of the two prototypes are given in Table $1 \sim 2$, and the selection range of optimization factors is determined, as shown in Table 3. The range of optimization factors is divided into 5 parts, and the level values of integer slot scheme are named A1, A2, A3, A4 and A5 from small to large; the level values of fractional slot scheme are named B1, B2, B3, B4 and B5 from small to large, as shown in Table 4.

Table 1. Main parameters of integer slot scheme.

\begin{tabular}{|c|c|c|c|}
\hline Parameters & Value & Parameters & Value \\
\hline Generator power & $10750 \mathrm{~kW}$ & Core length & $750 \mathrm{~mm}$ \\
\hline Pole of Pairs & 9 & Minimum air gap width & $4 \mathrm{~mm}$ \\
\hline Number of stator slots & 216 & Generator speed & $325 \mathrm{rpm}$ \\
\hline
\end{tabular}

Table 2. Main parameters of fractional slot scheme.

\begin{tabular}{|c|c|c|c|}
\hline Parameters & Value & Parameters & Value \\
\hline Generator power & $10750 \mathrm{~kW}$ & Core length & $700 \mathrm{~mm}$ \\
\hline Pole of Pairs & 12 & Minimum air gap width & $4 \mathrm{~mm}$ \\
\hline Number of stator slots & 180 & Generator speed & $315.4 \mathrm{rpm}$ \\
\hline
\end{tabular}

Table 3. Selection range of optimization factors.

\begin{tabular}{|c|c|}
\hline Optimization factor & Preferred range \\
\hline Polar arc coefficient & $0.65 \sim 0.85$ \\
\hline Skew angle / slot & $0 \sim 1$ \\
\hline
\end{tabular}


Table 4. Optimization factor levels.

\begin{tabular}{|c|c|c|c|c|c|}
\hline Optimization factor Horizontal factor & $\begin{array}{c}\text { A1 } \\
\text { (B1) }\end{array}$ & $\begin{array}{c}\text { A2 } \\
\text { (B2) }\end{array}$ & $\begin{array}{c}\text { A3 } \\
\text { (B3) }\end{array}$ & $\begin{array}{c}\text { A4 } \\
\text { (B4) }\end{array}$ & $\begin{array}{c}\text { A5 } \\
\text { (B5) }\end{array}$ \\
\hline Polar arc coefficient & 0.65 & 0.7 & 0.75 & 0.8 & 0.85 \\
\hline Skew angle / slot & 0 & 0.25 & 0.5 & 0.75 & 1 \\
\hline
\end{tabular}

\subsection{Establishment of orthogonal experiment}

According to table 4 and the construction principle of orthogonal table to establish orthogonal table. The finite element method is used to establish the corresponding number of motor models, and the experimental results are shown in Table 5. According to the experimental results, the average values of cogging torque and motor efficiency under different levels of optimization factors are calculated. The calculation results are shown in Table 6. According to the formula (12), the variance and its proportion of the optimization factor under the corresponding performance index can be calculated, as shown in Table 7.

Table 5. Orthogonal Table and Finite Element Results.

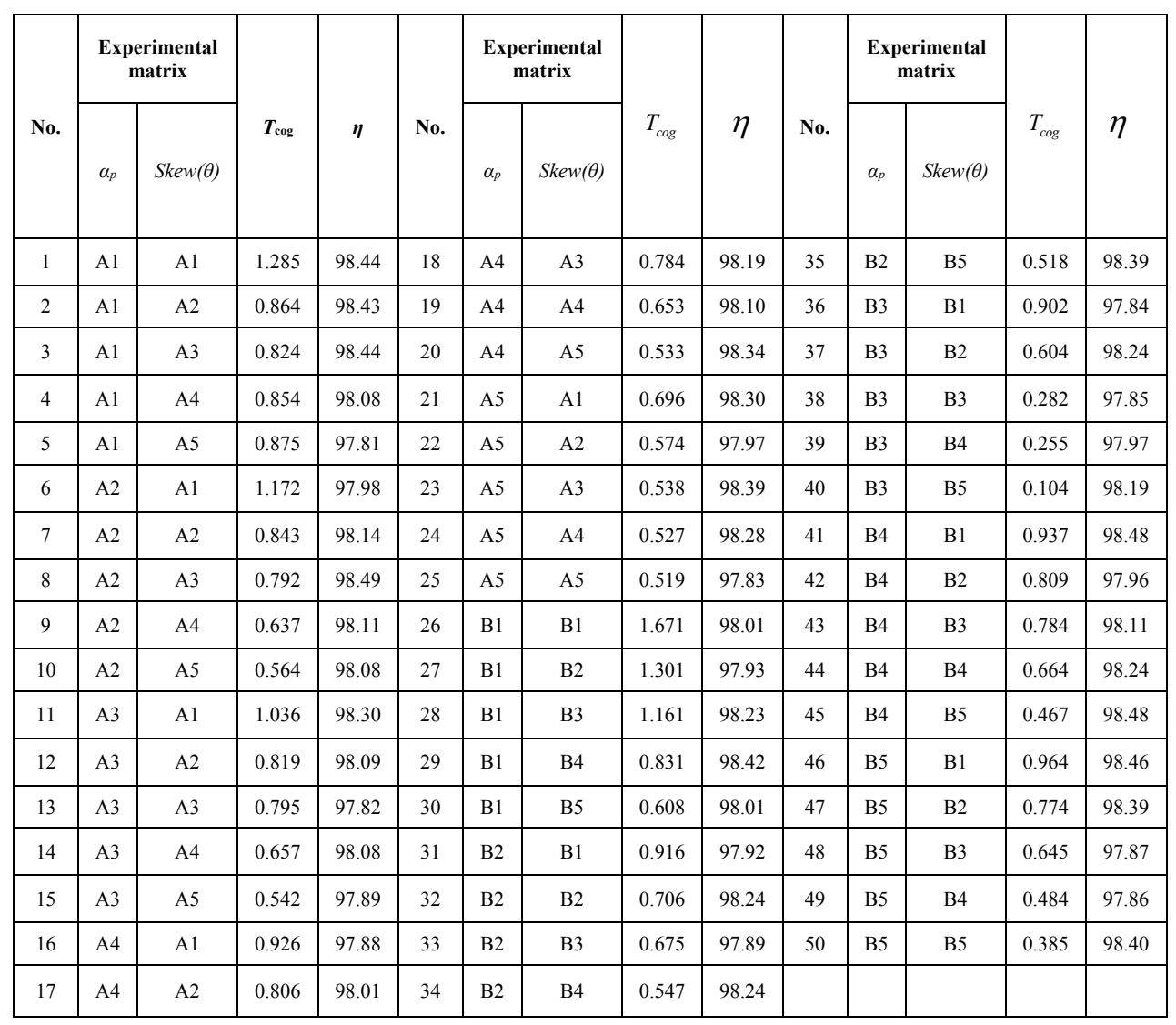


Table 6. Average values of optimization factors under different levels.

\begin{tabular}{|c|c|c|c|c|}
\hline Design scheme & Optimization factor & $\begin{array}{c}\text { Horizontal } \\
\text { value }\end{array}$ & $\begin{array}{c}\text { cogging } \\
\text { Zorque }(\mathbf{k N m})\end{array}$ & Efficiency \\
\hline \multirow{10}{*}{ Integer slot scheme } & \multirow{5}{*}{ Polar arc coefficient } & A1 & 0.940 & $98.24 \%$ \\
\hline & & A2 & 0.801 & $98.16 \%$ \\
\hline & & A3 & 0.769 & $98.04 \%$ \\
\hline & & A4 & 0.740 & $98.10 \%$ \\
\hline & & A5 & 0.570 & $98.15 \%$ \\
\hline & \multirow{5}{*}{ Skew angle / slot } & $\mathrm{A} 1$ & 1.023 & $98.18 \%$ \\
\hline & & $\mathrm{A} 2$ & 0.781 & $98.13 \%$ \\
\hline & & A3 & 0.746 & $98.27 \%$ \\
\hline & & A4 & 0.665 & $98.13 \%$ \\
\hline & & A5 & 0.606 & $97.99 \%$ \\
\hline \multirow{10}{*}{$\begin{array}{l}\text { Fractional slot } \\
\text { scheme }\end{array}$} & \multirow{5}{*}{ Polar arc coefficient } & B1 & 1.114 & $98.12 \%$ \\
\hline & & $\mathrm{B} 2$ & 0.672 & $98.14 \%$ \\
\hline & & B3 & 0.429 & $98.02 \%$ \\
\hline & & B4 & 0.732 & $98.25 \%$ \\
\hline & & B5 & 0.650 & $98.20 \%$ \\
\hline & \multirow{5}{*}{ Skew angle / slot } & B1 & 1.078 & $98.14 \%$ \\
\hline & & $\mathrm{B} 2$ & 0.839 & $98.15 \%$ \\
\hline & & B3 & 0.709 & $97.99 \%$ \\
\hline & & $\mathrm{B} 4$ & 0.556 & $98.15 \%$ \\
\hline & & B5 & 0.416 & $98.29 \%$ \\
\hline
\end{tabular}

Table 7. Variance and proportion of optimization factors under different performance indexes.

\begin{tabular}{|c|c|c|c|c|c|}
\hline \multirow{2}{*}{ Design scheme } & \multirow{2}{*}{ Optimization factor } & \multicolumn{2}{|c|}{ Cogging torque $T_{c o g}$} & \multicolumn{2}{|c|}{ efficiency $\eta$} \\
\hline & & Value & Proportion & Value & Proportion \\
\hline \multirow{3}{*}{ Integer slot scheme } & Polar arc coefficient & 0.014 & $41.17 \%$ & 0.0045 & $36.00 \%$ \\
\hline & Skew angle & 0.020 & $58.82 \%$ & 0.0080 & $64.00 \%$ \\
\hline & total & 0.034 & $100 \%$ & 0.0125 & $100 \%$ \\
\hline \multirow{3}{*}{$\begin{array}{c}\text { Fractional slot } \\
\text { scheme }\end{array}$} & Polar arc coefficient & 0.049 & $48.51 \%$ & 0.0062 & $40.25 \%$ \\
\hline & Skew angle & 0.052 & $51.49 \%$ & 0.0092 & $59.75 \%$ \\
\hline & total & 0.101 & $100 \%$ & 0.0154 & $100 \%$ \\
\hline
\end{tabular}

According to the table, the combination of optimization factors with the smallest cogging torque and the highest efficiency for the integral slot solution with integral slot windings is $\alpha_{\mathrm{p}}(\mathrm{A} 5)$ and $\operatorname{Skew}_{(\theta)}$ (A5), that is, the optimal pole arc coefficient is 0.85 , and the skew angle is 1 slot. The combination of optimization factors with the smallest cogging torque and the highest efficiency for the fractional slot concentrated winding with fractional slots is $\alpha_{\mathrm{p}}(\mathrm{B} 3)$ and $\operatorname{Skew}_{(\theta)}(\mathrm{B} 5)$. That is, the best pole arc coefficient is 0.75 , and the chute angle is 1 slot. Therefore, the optimal combination of optimization factors has been determined, and then the finite element simulation verification work is carried out on the calculation results of the Taguchi method. That is, the best pole arc coefficient is 0.75 , and the chute angle is 1 slot. Therefore, the optimal combination of optimization factors has 
been determined, and then the finite element simulation verification work is carried out on the calculation results of the Taguchi method.

\section{Simulation and verification of cogging torque of generator}

In this paper, two megawatt permanent magnet synchronous generator prototypes are designed as calculation examples. The integral slot scheme adopts integral slot winding, and the fractional slot scheme adopts fractional slot concentrated winding. The two prototypes are modeled respectively, and the pole arc coefficient and armature structure determined by Taguchi method are simulated and verified by finite element analysis. The The cross-sectional view cross sections of the two prototypes are shown in Fig 2.

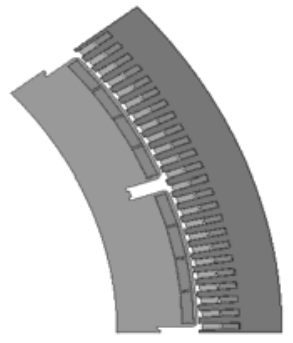

(a) 216 slot 18 pole design

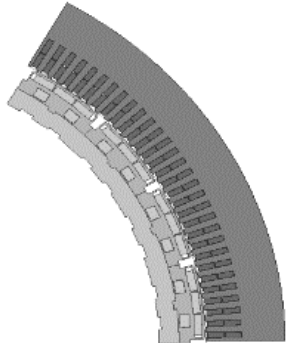

(b) 180 slot 24 pole design

Fig. 2. Sectional view of finite element model.

\subsection{Selection of pole arc coefficient of magnetic steel}

The pole arc coefficient in the built-in permanent magnet motor usually refers to the ratio of the pole arc length to the pole pitch. From the above analysis, it can be seen that the Fourier series expanded in the definition of cogging torque depends on the different number of slot poles.

According to the number of slot poles of the two prototypes, $B_{\mathrm{r}\left(\frac{\mathrm{nz}}{2 \mathrm{p}}\right)}(\theta)$ and $\xi^{2}(\theta, \alpha)$, which affect the cogging slot torque of the prototype, are respectively solved. The pole arc coefficient of one magnetic pole is taken as the independent variable to solve the pole arc coefficient of the other magnetic pole.

For the integer slot scheme, there are:

$$
\frac{\xi_{1} z_{1}}{2 p_{1}}=\frac{216}{18} n_{1}
$$

For the fractional slot scheme, there are:

$$
\frac{\xi_{2} z_{2}}{2 p_{2}}=\frac{180}{24} n_{2}
$$

Where, $\xi_{1}$ and $\xi_{2}$ are integers satisfying that $\frac{\xi z}{2 p}$ is an integer.

From the above formula, it can be concluded that the Fourier series that affects the cogging torque of the integer slot scheme is $12 \mathrm{k}$ ( $\mathrm{k}$ is an integer); the Fourier series that affects the cogging torque of the fractional slot scheme is $15 \mathrm{k}$ ( $\mathrm{k}$ is an integer). The curves of Brn changing with polar arc coefficient of two prototypes are shown in Fig. 3 and Fig. 4. 
It can be seen that the optimal polar arc coefficient of integer slot scheme is 0.85 , and that of fractional slot scheme is 0.75 , which is consistent with the results of Taguchi algorithm. The accuracy and reliability of the algorithm are further verified.

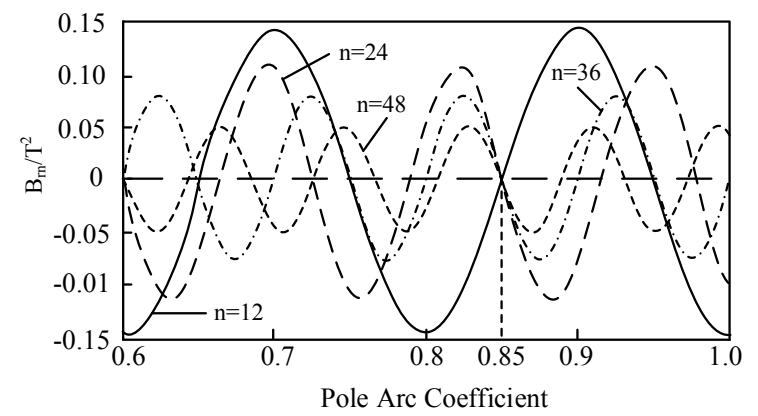

Fig. 3. Variation curve of $B_{r n}$ in integer slot scheme with pole arc coefficient.

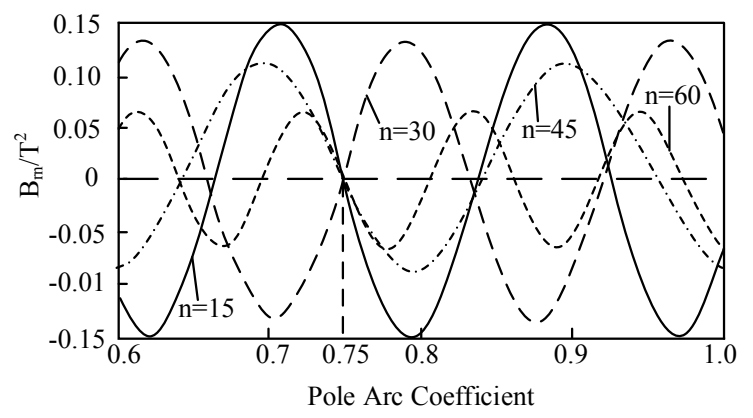

Fig. 4. Variation curve of $\mathrm{B}_{\mathrm{rn}}$ in fractional slot scheme with polar arc coefficient.

The parameter simulation of the polar arc coefficients of the two prototypes can be calculated based on the results of Taguchi algorithm. Among them, the curves 1-5 in Fig. 5 represent the waveform conditions when the pole arc coefficient is $0.65,0.7,0.75,0.8$ and 0.85 , respectively.

The influence of polar arc coefficient on cogging torque is shown in Fig. 5. In integer slot scheme, when polar arc coefficient is 0.85 , the cogging torque is smaller, which is $2.986 \mathrm{knm}$; In fractional slot scheme, when polar arc coefficient is 0.75 , the waveform sinusoidal of cogging torque is better, and the amplitude is smaller, which is about $0.963 \mathrm{kNm}$.

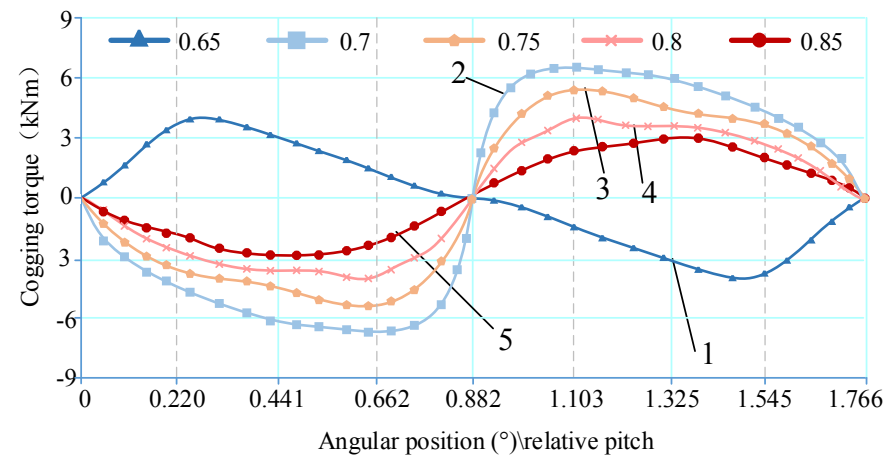

Fig. 5- (a). Variation of cogging torque in integer slot scheme under different pole arc coefficients. 


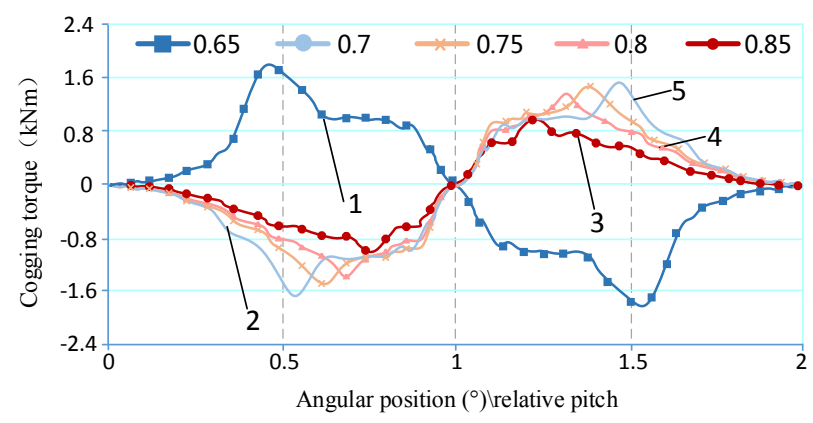

Fig. 5-(b). Variation of cogging torque in fractional slot scheme under different pole arc coefficients.

Fig. 5. The influence of pole arc coefficient on cogging torque.

\subsection{Selection of pole arc coefficient of magnetic steel}

According to the conclusion of Taguchi algorithm, the pole arc coefficient of integer slot scheme is 0.85 , and that of fractional slot scheme is 0.75 . The change of cogging torque with the change of chute angle is observed.

In Fig.6, it can be seen that the optimal skew angle of integer slot scheme with integral slot winding is 1 slot, and the cogging torque amplitude is about $500 \mathrm{~nm}$; the optimal skew angle of fractional slot scheme with fractional slot concentrated winding is 1 slot, and the cogging torque amplitude is about $120 \mathrm{~nm}$. It can be seen that the cogging torque can be reduced by $80 \%$ to $83 \%$ through the stator skewed slot winding. Under the same generator capacity, the cogging torque of using fractional-slot concentrated windings will be reduced by $90 \%$ to $94 \%$ compared to using integer-slot windings.

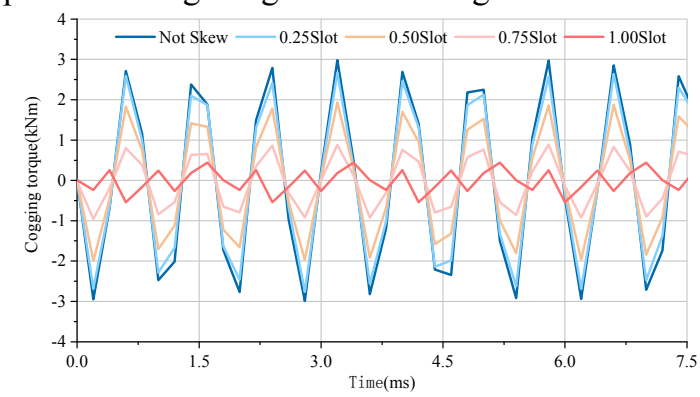

(a) Cogging torque change of integer slot scheme under different skew conditions

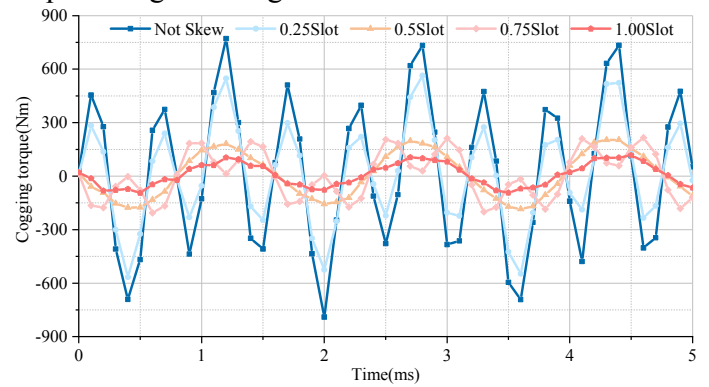

(b) Cogging torque changes of the fractional slot scheme under different skew conditions

Fig. 6. The influence of skew angle on cogging torque. 


\subsection{Simulation and optimization results and comparison of cogging torque}

After the optimization of the pole arc coefficient and the inclined chute angle, the higher harmonic of the induced electromotive force is reduced, which makes the waveform of the induced electromotive force have better sinusoidal. And the cogging torque suppression phenomenon is obvious, as shown in Fig. 7.

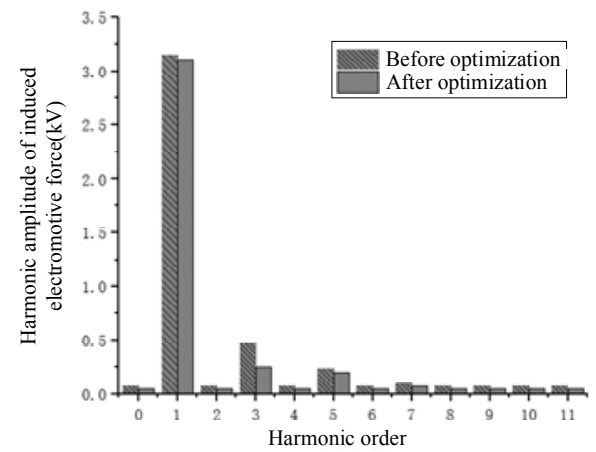

(a) Comparison chart of induced electromotive force harmonic analysis of integer slot scheme.

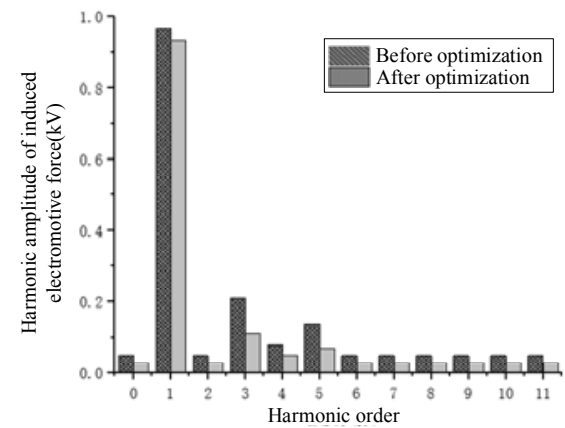

(b) Comparison chart of induced electromotive force harmonic analysis of fractional slot scheme.

Fig. 7. Comparison chart of no-load operation induced electromotive force harmonic analysis.

Table 8. Comparison of no-load induced electromotive force of the prototype.

\begin{tabular}{|c|c|c|c|}
\hline $\begin{array}{l}\text { Design } \\
\text { scheme }\end{array}$ & $\begin{array}{c}\text { Generator } \\
\text { model }\end{array}$ & $\begin{array}{c}\text { RMS value of no-load } \\
\text { voltage fundamental wave }\end{array}$ & $\begin{array}{c}\text { Fundamental RMS of load } \\
\text { phase current }\end{array}$ \\
\hline \multirow{3}{*}{$\begin{array}{l}\text { Integer slot } \\
\text { scheme }\end{array}$} & Original model & $3284.6 \mathrm{~V}$ & $1984.4 \mathrm{~A}$ \\
\hline & $\begin{array}{c}\text { Optimum pole arc } \\
\text { coefficient }\end{array}$ & $3277.3 \mathrm{~V}$ & $1995.8 \mathrm{~A}$ \\
\hline & $\begin{array}{l}\text { Optimize skew } \\
\text { angle }\end{array}$ & $3264.7 \mathrm{~V}$ & $1969.1 \mathrm{~A}$ \\
\hline \multirow{3}{*}{$\begin{array}{l}\text { Fractional } \\
\text { slot scheme }\end{array}$} & Original model & $938.3 \mathrm{~V}$ & $7169.4 \mathrm{~A}$ \\
\hline & $\begin{array}{c}\text { Optimum pole arc } \\
\text { coefficient }\end{array}$ & $942.5 \mathrm{~V}$ & 7177.3 A \\
\hline & $\begin{array}{l}\text { Optimize skew } \\
\text { angle }\end{array}$ & $940.7 \mathrm{~V}$ & $7165.8 \mathrm{~A}$ \\
\hline
\end{tabular}




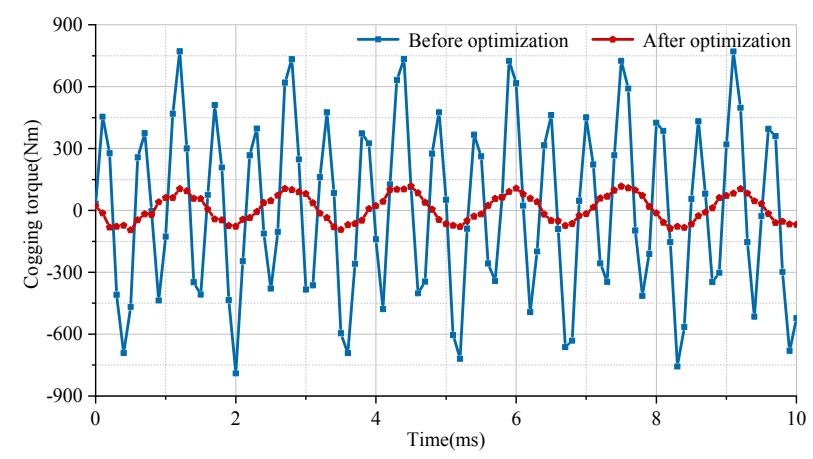

Fig. 8. Cogging torque waveform before and after integer slot scheme optimization.

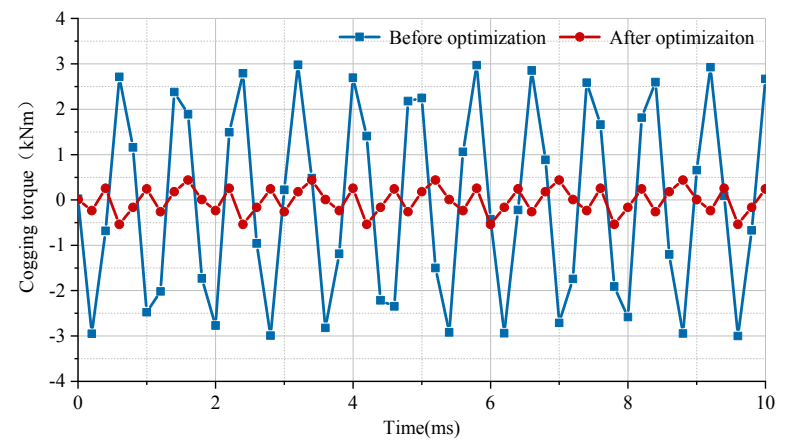

Fig. 9. Cogging torque waveform before and after fractional slot scheme optimization.

Through the analysis of the air gap flux density waveform, induced electromotive force waveform and output current waveform of the two optimized PMSG prototypes, it can be concluded that the motor performance of the two prototypes has not decreased after the optimization of cogging torque, the permanent magnets are running in a reasonable working range, and there is no demagnetization, which can reduce the cogging torque and meet the requirements Design requirements.

\section{Conclusion}

This paper optimizes the cogging torque problem in the design of PMSM. Based on the combination of Taguchi algorithm and finite element analysis, the optimization method of the contrastive analysis is proposed for the two prototype under different pole arc coefficient and chute angle. The following conclusions can be obtained:

(1) The orthogonal table of Taguchi algorithm is established, and it is concluded that pole arc coefficient and chute angle are the main influencing factors of generator cogging torque. The variance and influence proportion of the above two factors are used as the evaluation index of generator cogging torque amplitude.

(2) According to the variation of the pole arc coefficient, the best pole arc coefficient of the generator can be obtained, and with the variation of the pole arc coefficient, the variation range of the cogging torque amplitude can be up to two times different. The results show that the cogging torque amplitude decreases with the increase of the chute angle, and the maximum difference of the cogging torque amplitude can be $6 \sim 8$ times at the optimum chute angle. Therefore, the combination of the inclined slot and the best pole arc coefficient can greatly reduce the cogging torque amplitude, in order to make the operation of large capacity wind turbine more stable. 
(3) By combining the finite element simulation results with Taguchi algorithm, it is verified by two prototype tests. The test results show that the design idea of megawatt wind turbines combined with skew slot and pole arc coefficient can greatly reduce the cogging torque while the performance of the generator is guaranteed, which provides a reference for the design of large-capacity wind turbines.

\section{References}

1. Shoudao Huang, Ting Liu, Honglin Ouyang, Jian Gao. Permanent Magnet Motor Cogging Torque Reduction Method Based on Slot Offset[J].Transactions of the Chinese Society of Electrical Engineering,2013,28(03):99-106.

2. Jiaqi Liu, Jingang Bai, Ping Zheng, Guopeng Liu, Jiaxuan Huang .Study on Cogging Torque Based on the Principle of Magnetic Field Modulation[J].Transactions of the Chinese Society of Electrical Engineering,2020,35(05):931-941.

3. Xu Tang, Xiuhe Wang, Shumin Sun, Junwei Zhao. Analytical Analysis and Weakening Measures of Cogging Torque of Asynchronous Starting Permanent Magnet Synchronous Motor[J].Proceedings of the Chinese Society for Electrical Engineering,2016,36(05):1395-1403.

4. $\mathrm{Xu}$ Tang, Xiuhe Wang, Mengmeng Tian, Xiaoxue Meng. Research on Cogging Torque Weakening Measures of Asynchronous Start Permanent Magnet Synchronous Motor Based on Changing Stator Cogging Parameters[J].Transactions of the Chinese Society of Electrical Engineering,2016,31(23):1- 8.

5. Yubo Yang, Xiuhe Wang, Changqing Zhu. The Influence of Armature Slot Width on Cogging Torque of Built-in Permanent Magnet Synchronous Motor[J].Journal of Electrical Machines and Control,2011,15(07):21-25.

6. Yubo Yang, Xiuhe Wang, Tingting Ding, Xin Zhang, Zhang Ran, Changqing Zhu. Permanent Magnet Motor Cogging Torque Reduction Method Based on Pole Arc Coefficient Combination Optimization[J].Proceedings of the Chinese Society of Electrical Engineering,2007(06):7-11.

7. Zeyu Zhang, Zhiyong Jiao, Hongbing Xia, Peng Zhao, Shijian Su. Study on the Effect of Auxiliary Grooves on the Rotor Surface of Permanent Magnet Synchronous Motors on Cogging Torque[J/OL].Mechanical and Electrical Engineering,2019(12):13421346[2020-07 -26].

8. Yongxing Jin, Aiyuan Wang, Jian Sun, Tao Wang. Optimal Design of Noise and Cogging Torque of Permanent Magnet Synchronous Motor[J].Journal of Shanghai Dianji University,2019,22(02):68-72.

9. Shi Jiao, Zhiyong Lan, Lin Wang. Analysis of Electromagnetic Field and Cogging Torque of Surface-mounted Permanent Magnet Synchronous Motor Based on Analytical Method[J].Electrical Technology,2019,20(04):7-11.

10. Yantao Huang, Xinhua Guo, Leijun Xiang. Optimal Design of Cogging Torque of Built-in Permanent Magnet Motor[J].Journal of Huaqiao University(Natural Science Edition),2016,37(05):536-540.

11. Yanan Tang, Huicheng Jing, Xin Zhao, Zhichao Wang. Permanent Magnet Synchronous Motor Cogging Torque Optimization Design Simulation[J].Micro Special Motor,2019,47(01):28-32.

12. Qingling He, Qunjing Wang. Research on Cogging Torque Weakening Method of Permanent Magnet Synchronous Generator[J].Journal of Electronic Measurement and Instrument,2013,27(05):461-466. 
13. Feifei Liang. Research on Cogging Torque of Surface-mounted Permanent Magnet Synchronous Motor Based on Finite Element Analysis[D]. Zhejiang University of Technology, 2016.

14. Ke Liu. Study on the Influence of Permanent Magnet Motor Cogging Torque on the Initial Position of Resolver[J].Micromotor,2019,52(02):69-72.

15. Xiuhe Wang, Yubo Yang, Tingting Ding, Changqing Zhu, Wang Daohan.Research on Cogging Torque Weakening Method of Solid Rotor Permanent Magnet Synchronous Motor Based on Pole Arc Coefficient Selection[J].Proceedings of the Chinese Society of Electrical Engineering,2005(15):146-149.

16. Jiajie Zou, Shiwei Zhao, Xiangyu Yang. Optimization of Cogging Torque of Outer Rotor PMSM Based on Genetic Algorithm[J].Micro Special Motor,2020,48(04):1-6.

17. Xuejie Liu, Jin Zhou, Chaowu Jin, Dapeng Wang. Optimization of Cogging Torque of Low-speed Permanent Magnet Motor Based on RBF Approximate Model[J].Micro Special Motor,2020,48(01):25-29.

18. Yu Lei, Fugui Liu, Pengfei Wang. Permanent Magnet Synchronous Motor Cogging Torque Optimization Based on Improved TO Algorithm[J].Experimental Technology and Management,2019,36(11):146-149.

19. Jiabin Wen, Lan Yu. The Application of Taguchi Method in the Structural Optimization of Permanent Magnet Synchronous Motor[J].Journal of Harbin University of Science and Technology,2019,24(05):64-69.

20. Jianjun Li, Kaisheng Huang, Ning Wu, Qu Huang. Multi-objective Optimization of Surface Permanent Magnet Synchronous Motor Based on Taguchi Method[J].Micro Special Motor,2018,46(07):10-13.

21. Wenyao Cao, Bi Hu, Tuxiong Hu, Wei Wang. PMSM Cogging Torque Optimization Based on SVM-CSO Algorithm.[J].Explosion-proof Electric Machines,2018,53(04):14.

22. Haoyang Li. Research on Cogging Torque and Torque Ripple Mechanism and Optimization of Embedded Permanent Magnet Synchronous Motor[D]. Nanjing Normal University, 2018.

23. Zhifeng Zhang, Chunhai Zhu .Duty Cycle Direct Torque Control of Dual Three-phase Permanent Magnet Synchronous Motor[J].Journal of Shenyang University of Technology,2020,42(04):361-367.

24. Junqiang Lian, Hongkun Sun. Optimization of Cogging Torque of Marine Permanent Magnet Motor Based on PSO Algorithm[J].China Ship Research,2014,9(03):123-128 